\title{
O estatuto de nem na gramática do português
}

\author{
Norma Barbosa Novaes Marques* \\ Erotilde Goretti Pezatti**
}

\begin{abstract}
Resumo
Tradicionalmente a partícula 'nem' tem sido considerada uma conjunção aditiva, pois se entende que estabelece entre elementos uma relação de acréscimo. Etimologicamente, é proveniente do latim 'nec', um dos poucos juntores que restaram nas variedades vernáculas de latim, juntamente com 'et', 'aut', 'magis', 'ca', 'post' (cf. Nascentes, 1955). Para Neves (2000), 'nem' tem o mesmo papel de 'e', ou seja, é uma conjunção que marca uma relação de adição entre segmentos negativos coordenados, com significado básico de "e também não". Como se pode observar, a autora considera 'nem' um elemento complexo, indicando acréscimo por meio de 'e' e 'também', e negação, por meio de 'não'. Este trabalho tem como objetivo discutir o estatuto desse elemento, utilizando o aparato teórico da Gramática Discursivo-Funcional (HENGEVELD; MACKENZIE, 2008), tendo como hipótese a de que 'nem', tal como 'não', representa, morfossintaticamente, o operador de polaridade negativa, acrescida, no entanto, de ênfase. Para isso, utiliza o corpus do Projeto PHPB, constituído de documentos escritos no Brasil, dos séculos XVII ao XX. Os dados analisados revelam que 'nem' pode ocorrer numa relação de justaposição entre atos discursivos, ou entre termos de diferentes categorias semânticas, e representa, além da negação, uma estratégia de intensificação, utilizada pelo Falante para atingir seu propósito comunicativo.
\end{abstract}

Palavras-chave: Nem. Coordenação aditiva. Polaridade. Ênfase.

\section{Apresentação}

Este artigo tem como proposta discutir o estatuto de nem na gramática do português, sob a perspectiva da Gramática Discursivo-Funcional (HENGEVELD; MACKENZIE, 2008), utilizando o corpus do Projeto PHPB, constituído de

\footnotetext{
* União das Instituições Educacionais do Estado de São Paulo - UNIESP/José Bonifácio. Doutora em Estudos Linguísticos.

* Universidade Estadual Paulista 'Júlio de Mesquita Filho' UNESP/São José do Rio Preto. Doutora em Linguística e Língua Portuguesa.
} 
documentos escritos no Brasil, dos séculos XVII ao XX'1 . A hipótese que subjaz ao objetivo é a de que 'nem', tal como 'não', representa, morfossintaticamente, o operador de polaridade negativa, acrescida, no entanto, de ênfase. Dessa forma, o objetivo é mostrar que não se trata de uma conjunção aditiva, como tradicionalmente é entendida, mas sim de um operador complexo que indica, ao mesmo tempo, intensificação, uma categoria interpessoal, e negação, uma categoria semântica.

\section{Nem na literatura linguística}

Etimologicamente, nem é proveniente do latim nec, um dos poucos juntores que restaram nas variedades vernáculas de latim, juntamente com et, aut, magis, ca, post (Nascentes, 1955). Na passagem para o português, sofreu apócope do -c e acréscimo de "m", um efeito do "n" inicial, com sentido de "nem", "não" e "e não" (HOUAISS, 2009).

Tradicionalmente nem tem sido considerado uma conjunção aditiva (Cunha; Cintra, 2001; Bechara, 2004), pois se entende que estabelece com um primeiro elemento uma relação de acréscimo, como em (01), entre as orações "não podia votar" e "ser votado".

(01) não podia votar, nem ser votado. [CARleitorXIX1BA-15]

Neves (2000), no entanto, considera dois usos de nem: como advérbio de negação, exemplificado em (02), e como conjunção coordenativa, exemplificado em (03). Como advérbio, geralmente precedido de $e$, como em (04), está ao lado de não, que é o elemento básico de negação, e de outros elementos adverbiais negativos, como nunca e jamais, que mesclam ideia aspectual e temporal.

(02) A patroa quer dar umas voltinhas, nem quer saber do jogo. (NEVES, 2000, p. 287)

(03) Mas como era sujeito distinto, não telefonou nem procurou pessoalmente Monticelli. (NEVES, 2000, p. 287)

(04) De sorte que não poderia, e nem deveria vir, no bojo de um mesmo processo, uma matéria fundamental, uma matéria urgente como a que V. Ex. se refere. (NEVES, 2000, p. 753)

$16 \mathrm{O}$ Projeto para a História do Português Brasileiro (PHPB) é constituído de corpora diacrônicos escritos no Brasil, nos séculos XVI, XVIII, XIX e XX. Trata-se de documentos de natureza variada: impressos e manuscritos, de esferas institucional pública, institucional privada e particular, textos manuscritos mais formulaicos e textos menos formulaicos. 
Para a autora, nem é o único elemento de negação que, além de seu papel adverbial, pode ser usado como conjunção. No caso de (03), nem tem o mesmo papel de $e$, ou seja, é uma conjunção que marca uma relação de adição entre segmentos negativos coordenados, com significado básico de "e também não". Como se pode observar, a autora considera nem um elemento complexo, pois indica acréscimo, por meio de $e$ e de também, e negação, por meio de não. Afirma ainda que a diferença entre $e$ e nem é que o segundo adiciona "segmentos negativos e privativos", como em (05) e (06):

(05) Detetives não acharam rastro de Enrico nem da Bertolazzi. (NEVES, 2000, p. 752)

(06) Um homem de bem neste estado, sem saber como nem por quê! (NEVES, 2000, p. 752)

Segundo Neves (2000), ao adicionar elementos negativos ou privativos, nem tem um significado denso, marcado, o que favorece o emprego de palavras de reforço, como em nem tampouco (acréscimo), nem mesmo (inclusão) e nem ao menos (privação). A autora não esclarece, no entanto, a que se referem os termos "denso" e "marcado". Reconhece ainda Neves casos de nem como elemento juntor aditivo em orações denominadas correlativas, conforme (07).

(07) Nem ela me ofereceu a mão da amizade e do bom conselho nem eu jamais respondi com quatro pedras na mão. (NEVES, 2000, p. 752)

Rosário (2009), assim como Neves (2000), considera que as denominadas aditivas com nem...nem são correlativas, diferentemente de Módolo (1999), que, ao tratar da correlação, não inclui essas construções.

Para Módolo (1999), a correlação é um "tipo de conexão sintática de uso relativamente frequente, particularmente útil para emprestar vigor a um raciocínio, aparecendo principalmente nos textos apologéticos e enfáticos" (MÓDOLO, 1999, p.3), e preferencialmente se presta a expressar opinião, defender uma posição, mais do que para informar acontecimentos com objetividade. Em frases correlativas, há uma relação de interdependência, ou seja, a estrutura das sentenças que se correlacionam está estreitamente vinculada por expressões conectivas, como mostra (08), em que não só...mas também ilustra um caso de correlação aditiva:

(08) Ao obrigar a rede de $2^{\circ}$ grau a preparar seus alunos para essas provas, a UNICAMP deu uma contribuição decisiva não só para a renovação pedagógica nos bons colégios públicos e privados mas, também, para a própria transformação dos livros didáticos (...). (JT 27/05/93) 
Rosário (2009) defende que as correlatas são marcadas em relação às coordenadas, com base nos seguintes argumentos: tendem a ser mais complexas em termos de estrutura, já que vêm aos pares, de forma interdependente; são bem menos frequentes (diferentemente do que aponta Módolo, 1999), e mais complexas do ponto de vista cognitivo, pois exigem maior esforço mental e demandam maior tempo de processamento.

Rodrigues (2014), por outro lado, descreve as construções com nem...nem, juntamente com ora... ora, seja... seja, inserindo-as no grupo das correlativas alternativas, pois, segundo a autora, o que é dito sobre a primeira oração não vale para a segunda, como em (09):

(09) quando foi lavar a boca assim na - olhou pro lado assim (vinha) um navio estava pertinho já daqui pra ali não tinha tempo de dos cara fazer nada nem ligar o motor / nem nada pra sair fora né o navio estava em cima já aí um um um falou assim ó pula n'água todo mundo. (RODRIGUES, 2014, p. 134)

Para Rodrigues $(2007,2014)$, na correlação, há uma relação de interdependência estrutural entre as duas orações, estabelecida por elementos formais que compõem um par correlativo, estando cada um de seus componentes em orações diferentes. A autora aponta as seguintes características da correlação: os conectores vêm aos pares, estando cada elemento do par em uma oração; as orações não são constituintes uma da outra e não podem ter sua ordem invertida. Concordando com Castilho (2010, p. 389, apud RODRIGUES, 2014, p. 130), Rodrigues considera que as correlatas alternativas diferem das demais correlatas, pois permitem a mobilidade das orações.

Em síntese, é possível perceber que os estudos sobre nem indicam que: i) pode ser um advérbio ou uma conjunção, conforme aponta Neves (2000); ii) como conjunção, pode estar em estruturas coordenadas ou correlatas (NEVES, 2000; ROSÁRIO, 2009; RODRIGUES (2014); e iii) a oração que encabeça é "marcada" (NEVES, 2000; ROSÁRIO, 2009).

\section{Construções com nem no português}

O material analisado, constituído de documentos escritos no Brasil, dos séculos XVII ao XX, mostra que nem ocorre em três diferentes tipos de construções no português, conforme demonstram (10), (11), (12) e (13).

(10) este pedante nem Logica estudou [CARleitorXIX1PE-4] 
(11) Não lhe retribuimos na mesma moeda; nem transcrevemos taes escriptos [1CARedatorXIX1RJ-343]

(12) Para a hora da cea não chamava ninguém, nem queria assistencia de criado pera ella, nem pera o descalçar quando se deitava, nem pera o vestir quando se levantava. [XVII -A Camara e Gouerno da notauel Villa de Viana]

(13) Nem na noite passada nem nesta permitio otempo fazer observaçaõ alguma. [XVIII -Diário de viagem]

Em (10), a oração com nem não se encontra relacionada a outra oração, sendo, portanto, independente, cabendo a nem apenas o papel de advérbio de negação, conforme entende Neves (2000). Em (11), há duas orações independentes, "não lhe retribuimos na mesma moeda" e "nem transcrevemos taes escriptos", e em (12), duas orações subordinadas finais reduzidas de infinitivo, "nem pera o descalçar quando se deitava" e "nem pera o vestir quando se levantava". Em (13) ocorre a junção de dois sintagmas, "na noite passada" e "nesta [noite]".

O tipo de construção com nem que mais tem recebido a atenção dos estudiosos é, sem dúvida, a de duas orações independentes combinadas, processo denominado de coordenação de orações, como exemplificado em (11).

Conforme se observa em (11) e a seguir em (14) e (15), uma exigência de nem em coordenação de orações, independentes ou subordinadas, é a de que haja um elemento negativo no primeiro membro da relação aditiva, como não, em (11); ninguém, em (14), e nunca, em (15):

(14) Ninguém ouvio, nem ousará affirmal-o que Luiz Fernandes requeresse protesto algum, que para tanto não chegaria o seo discernimento[CARleitorXIX1BA $-15]$

(15) Nas antigas Republicas, e mesmo nas Monarquias, nunca o Povo teve I reprezentantes, nem semelhante tremo hera conhecido. [CARleitorXIX1PE-4]

Há ainda a possibilidade de esse elemento negativo do primeiro membro da coordenação ser a forma nem, como em (12) e (13), e assim formam-se estruturas com nem...nem, consideradas como correlação, por autores como Rosário (2009) e Rodrigues (2014).

Entendemos, porém, que, no caso de nem, a relação entre as duas partes não implica que a presença de um dos elementos prepara para a enunciação de outro. Assim, não se trata do caso de correlação descrito por Oiticica (1952), em que uma sentença estabelece uma relação de interdependência com a outra no nível estrutural. Nas construções com múltiplos nem, não há relação de interdependência 
entre as orações, conforme demonstra (17).

(17) não tinha tempo de dos cara fazer nada nem ligar o motor / nem nada pra sair fora. (Rodrigues, 2009)

Como se pode perceber, o uso de nem não cria expectativa de acréscimo de um segundo elemento. Como mostra (17b), não se faz necessária a complementação com a segunda oração iniciada por nem, diferentemente do que ocorre com (18), com não somente...mas também, um exemplo de correlação dado por Módolo (1999).

(17) a. não tinha tempo de dos cara fazer nada nem ligar o motor / nem nada pra sair fora.

b. não tinha tempo de dos cara fazer nada nem ligar o motor.

(18) a. Não somente Marilda socorreu a pobre família, mas também adotou as duas órfãs.

b. * Não somente Marilda socorreu a pobre família

Evidentemente, as estruturas de (17)a e b, são diferentes. Pode-se perceber, no entanto, em (17a), a possibilidade de expansão com mais enunciados introduzidos por nem, como em $(17 \mathrm{c})$, o que demonstra tratar-se de coordenação n-ária por justaposição e não de estruturas correlatas.

(17) c. não tinha tempo de dos cara fazer nada nem ligar o motor / nem nada pra sair fora nem nada para continuar tentando se livrar do problema.

Essa propriedade de negação enfática de vários elementos é claramente observada em (19), em que ocorrem várias orações coordenadas por justaposição, iniciadas por nem: "per socorrer a duas companhias", "pera armar os que podião seruir pera a defensão", "pera se darem as moniçoens, $\&$ poluora", "pera se pòr a artelharia onde fizesse danno ao inimigo", "pera mais que pera saluar as vidas sem respeito das honras":

(19) Bem se deixa ver a confusaõ, \& tumulto em que ficaria aquella Cidade, entrada com tam subita força, \& deixada com tanto desacrodo, desgouerno, \& desbarate, que nem ouue prouidencia pera se impedir a desembarcação, onde fosse de proueito; nem per socorrer a duas companhias, que a esse effeito mandaram: nem pera armar os que podião seruir pera a defensão; nem pera se darem as moniçoens, \& poluora, a quem com fruto pudesse gastallas: nem pera se pòr a artelharia onde fizesse danno ao inimigo: nem pera mais que pera saluar as vidas sem respeito das honras, como por muytas cartas foy Sua Magestade bem auisado. [XVII Do fundamento que os Olandezes tiueraõ pera tratar] 
Essas constatações nos levam a propor que nem não representa um juntor aditivo como comumente se afirma, o que será discutido nas próximas seções.

\section{Pressupostos teóricos da GDF}

A Gramática Discursivo-Funcional é um modelo teórico que privilegia a intenção comunicativa do falante ao fazer uso do sistema linguístico em situação de interação. A GDF propõe que o componente gramatical está em níveis (pragmático, semântico, morfossintático e fonológico), que se apresentam como autônomos, por contarem com categorias próprias, mas interdependentes, devido à possibilidade de motivações semânticas e pragmáticas determinarem a codificação morfossintática e fonológica.

Um pressuposto da teoria é a separação entre os processos de Formulação e Codificação na produção linguística. No primeiro processo, o foco é a especificação de configurações pragmáticas (denominadas interpessoais) e semânticas (denominadas representacionais), enquanto, no segundo, observamse as configurações morfossintáticas e fonológicas, ou seja, as unidades formais que as configurações pragmáticas e semânticas acarretam em uma língua. A Formulação converte a intenção comunicativa e sua representação mental em representações interpessoais e representacionais, enquanto a Codificação transporta as representações interpessoais e representacionais para os níveis morfossintático e fonológico, configurando uma expressão linguística.

As relações de Formulação e Codificação encontram-se estruturadas em níveis que são representados hierarquicamente em organização descendente, que vai do discurso para a forma das expressões linguísticas; assim, a pragmática governa a semântica; a pragmática e a semântica comandam a morfossintaxe e, por fim, a pragmática, a semântica e a morfossintaxe governam a fonologia.

Há quatro níveis de análise. Dois deles referem-se à formulação: o Nível Interpessoal diz respeito à interação entre Falante e Ouvinte e representa as ações linguísticas do Falante para conseguir seu objetivo comunicativo, cujo sequenciamento reflete a ordem das estratégias colocadas em prática para o falante atingir seu objetivo comunicativo, enquanto o Nível Representacional trata dos aspectos semânticos das unidades linguísticas, quer referentes ao modo como a língua se relaciona ao mundo extralinguístico que ela descreve, quer aos significados de unidades lexicais, independentemente do modo como essas 
unidades são usadas na comunicação. Os outros dois, o Nível Morfossintático e o Fonológico, dizem respeito à codificação, ou seja, têm como tarefa tomar o input duplo resultante da formulação dos níveis Interpessoal e Representacional e convertê-lo em unidades de conteúdo morfossintático (composição sintática e morfológica dos elementos linguísticos) ou fonológico (aspectos da codificação não abrangidos pelo Nível Morfossintático).

Os níveis também são hierarquicamente estruturados em camadas de vários tipos, em que a camada mais alta contém outra camada, que contém outra e assim sucessivamente. Cada camada tem obrigatoriamente um Núcleo, que pode ser restringido por um Modificador, especificado por um Operador e ter ainda uma Função. Núcleos e Modificadores constituem estratégias lexicais, já Operadores e Funções, estratégias gramaticais. Uma Função ocorre entre unidades da mesma camada, por isso é sempre relacional, enquanto um Operador se aplica a uma unidade em si mesma. A Figura (1) apresenta o layout da GDF:

FIGURA 1. Layout geral da GDF (HENGEVELD e MACKENZIE, 2008, p. 13)

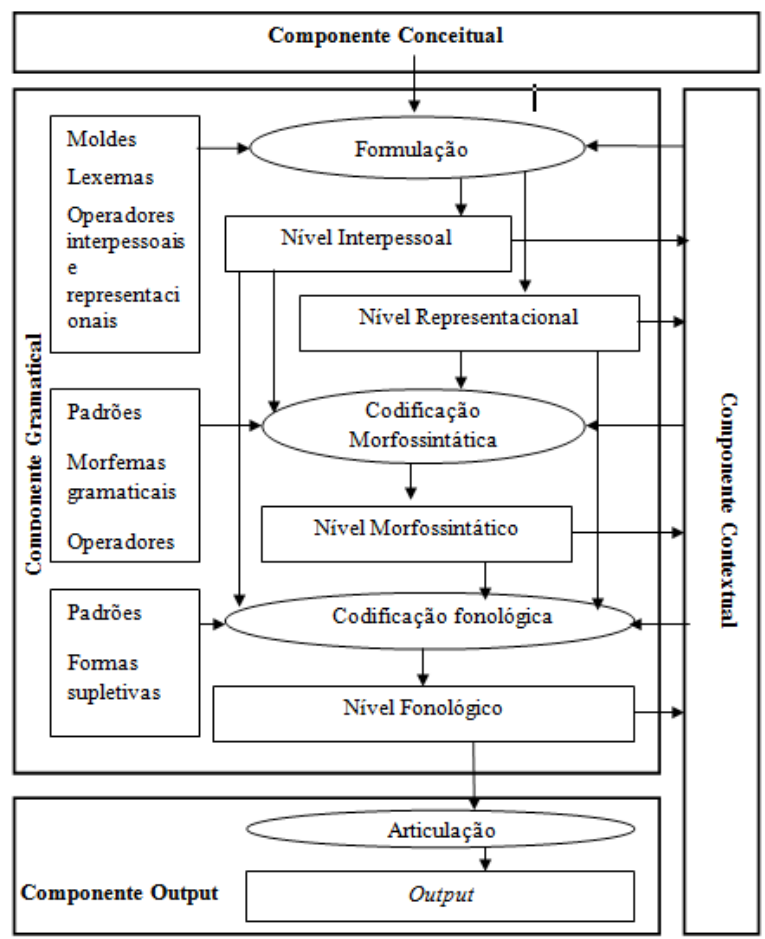


Os vários níveis de representação dentro da gramática alimentam o Componente Contextual, tornando possível subsequente referência a vários tipos de entidades relevantes introduzidas no discurso em cada um desses níveis. O Componente Contextual alimenta as operações de Formulação e Codificação, uma vez que disponibiliza antecedentes, referentes visíveis, e participantes do ato de fala que podem de alguma forma influenciar a composição do Ato Discursivo subsequente. O Componente Conceitual não faz parte da gramática, mas é a força motriz que está por trás do componente gramatical.

Os conceitos da GDF pertinentes para a análise do item nem serão mais detalhadamente discutidos na próxima seção.

\section{0 estatuto de nem no português}

Em construções como (21), em que nem ocorre em uma oração independente, é possível perceber que o falante pretende negar enfaticamente o conteúdo comunicado "todos tem as mesmas posses". Em outras palavras, estrategicamente ele intensifica uma informação que julga importante para atingir seu propósito comunicativo.

(21) Vossa mercê mesmo me acaba de dizer que a mocidade está enthusiasmada, e que todos querem estudar; nem todos tem as mesmas posses; uns são ricos, outros pobres. [1CARleitorXIX1SP -217]

$\mathrm{Na}$ GDF, a intensificação, por meios lexicais ou gramaticais, de um constituinte ou de toda a expressão linguística é denominada Ênfase. A Ênfase refere-se a uma categoria pragmática que perpassa todas as camadas do Nível Interpessoal, já que configura uma estratégia a mais, utilizada pelo Falante para atingir seu propósito comunicativo. É exatamente isso que faz a partícula nem em (21): intensifica o constituinte que a segue.

Por vezes a Ênfase é vista como uma contraexpectativa, como em (22), em que o uso de nem intensifica a indignação do Falante por considerar que as leis já deveriam ter sido executadas. Nesses casos, nem pode ser substituído por sequer, como mostra o trecho em (22a), considerado pela tradição como indicador de ênfase.

(22) Mas terá o povo Pernambucano experimentado todo o bem, que esperar podia das quatro sessões passadas? Não tem elle visto com magoa gastar se tantas vezes o tempo precioso em questões innuteis, e mesmo dictadas pelo espirito de 
partido? Não tem elle sentido o gravame de novas contribuições? Não tem elle conhecido a inutilidade da multidão de Leis, das quaes muitas nem executadas tem sido? [3CARredatorXIX1PER-20]

(22) a. Não tem elle conhecido a inutilidade da multidão de Leis, das quaes muitas sequer executadas tem sido?

Em estruturas de coordenação de sintagmas, como em (23), (24) e (25), o caráter de intensificador do segundo membro veiculado por nem pode ser claramente constatado.

(23) Havia de reprezentar sua justiça allegando, que ao Donatario competia Quanto ao estilo da historia, \& à lingoagem Portuguesa que leuo no discurso della, não tenho que me alargar em disculpas nem abonações, pois cada hum pratica conforme ao estilo, que lhe cõmunicou a natureza. [(XVII-Do fundamento que os Olandezes tiueraõ pera tratar]

(24) Sua vitória, no entanto, estava longe de representar a vontade da maioria: só puderam votar homens maiores de 21 anos que não fossem mendigos, analfabeto, praças, nem padres. [1CAReditoriaisXX2PE-90]

(25) A copa, ou Aparador de estado, em que os vãos do mundo se revem (\& ãs vezes com fausto mintiroso, porque acontece serem mais as dividas de seus donos, do que val tudo o que nelle enlea os olhos) era pera o Arcebispo hua banca seca da arquitectura das que cõtamos da sua camara sem toalha, sem vazo, nem prato, nem peça outra de prata. [XVII - Prologo do Avthor aos Leitores]

Em (23), nem nega enfaticamente o segundo membro da listagem ("abonações"); em (24), o termo padres, relacionado a vários outros anteriormente apresentados (mendigos, analfabeto, praças); em (25), é usado para negar os dois últimos termos (prato, peça outra de prata) dentre vários já negados anteriormente pela preposição sem (toalha, vazo), na listagem. No exemplo (25), nem e sem têm a mesma propriedade, a de negação, o que reforça a ideia de que nem não é uma conjunção.

Como já observado, é comum atribuir-se a esse elemento o papel de juntor aditivo, em uma relação de coordenação. No entanto, uma análise mais atenta permite observar o que segue.

A coordenação, segundo Dik (1997b) é um processo linguístico de expansão de uma estrutura em séries coordenadas de elementos similares. O seguinte esquema fornece uma representação formal desse processo:

$$
\alpha \rightarrow \alpha^{1}, \alpha^{2}, \ldots, \alpha^{\mathrm{n}}(\mathrm{n} \geq 2)
$$


Essa representação opera sobre algum elemento $\alpha$, expandindo-o numa série n-ária de elementos coordenados do mesmo tipo. Assim, a construção coordenada consiste em dois ou mais membros, funcionalmente equivalentes, combinados no mesmo nível estrutural por meio de mecanismos de ligação. Isso implica que nenhum dos membros de uma construção coordenada é subordinado aos demais, embora possam mostrar relações de dependência maior ou menor. Eles estão todos par a par e são membros iguais da coordenação $(\mathrm{CO})$, tendo, portanto, equivalência funcional.

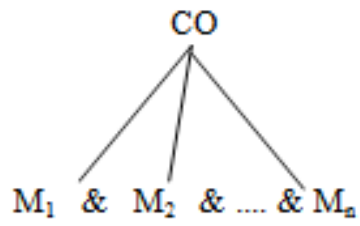

Isso significa que nenhuma unidade é constituinte da outra, quer dizer, cada uma pode ocorrer sozinha, mas a combinação delas constitui uma única unidade formal, podendo ser representada como em (26), em que cada relatum representa um membro da combinação e R, o mecanismo de ligação.

(26) [Relatum] R [Relatum]

As ocorrências de (11) a (13), repetidas aqui por conveniência, ilustram isso perfeitamente. Em (11), há duas orações independentes coordenadas, em que "nem transcrevemos taes escriptos" é uma expansão de "não lhe retribuimos na mesma moeda", formando assim uma expressão composta por dois membros funcionalmente equivalentes. O mesmo ocorre em (12), em que há uma coordenação de duas orações subordinadas, pois "nem pera o descalçar quando se deitava" e "nem pera o vestir quando se levantava" se combinam para formar uma unidade formal. Nos dois casos, nenhuma das unidades é constituinte da outra. Esse mesmo processo de expansão ocorre em (13), entre os sintagmas "na noite passada" e "nesta [noite]".

(11) Não lhe retribuimos na mesma moeda; nem transcrevemos taes escriptos [1CARedatorXIX1RJ-343]

(12) Para a hora da cea não chamava ninguém, nem queria assistencia de criado pera ella, nem pera o descalçar quando se deitava, nem pera o vestir quando 
se levantava. [XVII -A Camara e Gouerno da notauel Villa de Viana]

(13) Nem na noite passada nem nesta permitio otempo fazer observaçaõ alguma. [XVIII -Diário de viagem]

$\mathrm{Na}$ GDF, a coordenação é entendida como um processo de expansão que ocorre no Nível Morfossintático, como consequência da junção de dois Atos Discursivos, no Nível Interpessoal. Em outras palavras, a coordenação ocorre na camada mais alta do Nível Morfossintático, a da Expressão Linguística. A Expressão Linguística refere-se a qualquer conjunto constituído de, pelo menos, uma unidade morfossintática, que pode ser Oração, Sintagma ou Palavra. No caso da coordenação, a Expressão Linguística é composta de duas ou mais orações independentes, que, no Nível Interpessoal, correspondem a Atos Discursivos, cuja combinação resultante constitui uma única unidade formal.

O Ato Discursivo é a menor unidade linguística do comportamento comunicativo que corresponde a uma unidade de entonação com diferentes graus de complexidade: é geralmente composto de uma Ilocução e de um Conteúdo Comunicado, e é emitido por um falante e dirigido a um destinatário. A Ilocução captura as propriedades formais e lexicais do Ato Discursivo que podem ser atribuídas ao seu uso interpessoal convencionalizado para alcançar uma intenção comunicativa. As intenções comunicativas incluem ações como chamar a atenção, afirmar, dar ordem, questionar, alertar, requerer etc., que podem determinar Ilocuções do tipo Vocativo, Declarativo, Imperativo etc.

Como se pode observar, em (11), há dois Atos discursivos, com ilocução declarativa, visto que o falante instrui o destinatário a adicionar o conteúdo comunicado à sua informação pragmática. Assim considerando, da perspectiva da GDF, apenas a ocorrência (11) constitui um processo de coordenação.

Casos como (13), por outro lado, sob o ponto de vista da GDF, ocorrem numa Expressão Linguística formada com a combinação de sintagmas e/ou de palavras, constituindo uma listagem. Dik (1989) denomina essa junção de coordenação de termos, e a entende como um modo abreviado e econômico de expressar que diferentes entidades se relacionam da mesma maneira com o predicado, permitindo manifestar dois estados-de-coisas com uma única oração. Visto que cada um dos termos estabelece uma relação independente com o predicado, esse tipo de coordenação pode facilmente ser explicado por multiplicação direta.

De qualquer forma, esses casos constituem expansão de elementos, orações ou sintagmas, funcionalmente equivalentes, combinados no mesmo nível estrutural, por meio de mecanismos de ligação. 
Retomando Dik (1997b), na coordenação, o mecanismo de ligação (R) pode não estar evidente, havendo, então, a colocação lado a lado de dois membros, sem qualquer conectivo, e separados por uma pausa, que se indica, na escrita, por vírgula, ponto-e-vírgula ou dois pontos, o que caracteriza a justaposição.

Como pode ser observado pelas paráfrases de (11), (12) e (13), em (11)a, (12)a e (13)a, a relação de adição entre os membros coordenados é efetuada por justaposição, sendo possível a inserção da conjunção $e$ no lugar da vírgula para estabelecer, sem qualquer prejuízo, a relação aditiva pretendida.

(11) a. Não lhe retribuimos na mesma moeda $e$ nem transcrevemos taes escriptos.

(12) a. nem pera o descalçar quando se deitava e nem pera o vestir quando se levantava.

(13) a. Nem na noite passada e nem nesta permitio otempo fazer observaçaõ alguma.

Como se observa tanto pelas paráfrases anteriores quanto por ocorrências como (27) e (28), e e nem podem co-ocorrer, o que sugere que $e$ é o elemento juntor entre "naõ quero" e "nem me convem", em (28), e entre "com $120 \$$ rèis votados em 1848 para o material da Typographia Provincial" e "com $4 \$ 960$ rèis despendidos com o concerto do prelo", em (28). Dessa forma, resta a nem indicar apenas a negação, o que corrobora a afirmação de Neves (2000) de que nem é um advérbio.

(27) todavia naõ quero e nem me convem romper contra o mesmo, somente fundado em suspeitas; por isso desafio ao meu detractor para que saia de detràs do reposteiro que lhe prometto responder cathegoricamente, e desmascaral-o [1CARleitorXIX1CE -resposta a insultos recebidos]

(28) Está pois demonstrado que o tal contrato prejudicava os cofres Provinciaes em ais de um conto e quinhentos mil rèis; vê-se porém que nao contei com $120 \$$ rèis votados em 1848 para o material da Typographia Provincial, e nem cois despendidos com o concerto do prelo, e mandados pagar por despacho de 30 de Julho, por que entao subis á $1.648 \$ 960$ réis. [1CarLeitoresXIX1SC]

Os exemplos mostram ainda que a co-ocorrência de $e$ e nem pode ser observada tanto entre orações principais, conforme (27), como entre sintagmas, em (28), e também em orações independentes, como em (29):

(29) Em fevereiro de 1829 foi segunda vez reeleito Juiz de Paz desta Freguesia, jasendo molesto em uma cama ungido e sacramentado, sem esperanças de vida, 
o que era notorio a todos os seos comparochianos, e nem assim divergiram seos votos; verdade esta constante da Acta d'aquellas Eleições: e qual seria Senhor Redactor, o motivo de ser reeleito, como foi, senão a boa opinião publica, que este Juiz gosa nesta Freguesia? [CARleitorXIX1BA-15]

A possibilidade de substituição da vírgula por $e$ e a co-ocorrência de $e$ e nem sugerem que nem é, na verdade, um elemento de negação, seja de Estados-decoisas, representados por orações, conforme exemplos anteriores, seja de outras categorias semânticas, como propriedade, indivíduo, lugar, modo, conforme exemplificam respectivamente (30), (31), (32) e (33):

(30) O que não pode nem deve é continuar a atual norma antiquada e retrograda, em que o fornecedor vende por preços bem elevados, porque tem no governo um pagador relapso por várias implicações [1CARredatorXX2CE]

(31) Eu nunca pedi utencilios para a minha Aua, nem caza ou alugueres para se pagar. [1CARleitorXIX1CE]

(32) O inventario continúa no mesmo, nem para traz nem para adiante, o que de certo não agrada muito aos credores. [Carta Leitor XVII PE -36]

(33) que eu naõ tenho tomado parte em dita revolta, nem directa nem indirectamente; e que, finalmente, pronunciei-me e pronuncio-me contra esse partido. [CARleitorXIX1PE-17]

O Estado-de-coisas é uma camada do Nível Representacional que pode ser localizada no tempo relativo e avaliada em termos de seu estatuto de realidade, já que pode ocorrer ou acontecer em algum ponto de um intervalo de tempo. Hierarquicamente abaixo do Estado-de-coisas, está a Propriedade Configuracional, não caracterizada em termos de tempo e espaço, uma vez que só pode ser avaliada em relação a sua aplicabilidade a outros tipos de entidades ou à situação que ela descreve, não tendo, portanto, existência independente. As demais categorias semânticas não são hierárquicas: indivíduo, entidade concreta, tangível, que pode ser localizada no espaço e avaliada em termos de sua existência, e lugar, tempo, modo, quantidade e razão, categorias em que os próprios nomes explicitam o valor semântico.

Como mostram essas ocorrências, uma propriedade importante de nem é poder negar Estados-de-coisas ou qualquer categoria semântica hierarquicamente inferior, o que não é possível com não, que só pode negar Estados-de-coisas ou propriedades. Note-se a impossibilidade de paráfrases com não em (31)a, (32)a e (33)a, casos de indivíduo, lugar e modo, respectivamente: 
(31) a. Eu nunca pedi utencilios para a minha Aua, não caza ou alugueres para se pagar.

(32) a. *O inventario continúa no mesmo, nem para traz não para adiante, o que de certo não agrada muito aos credores.

(33) a. *que eu naõ tenho tomado parte em dita revolta, nem directa não indirectamente; e que, finalmente, pronunciei-me e pronuncio-me contra esse partido.

Ao fazer uso de nem, em vez de não, o falante estrategicamente intensifica uma informação que julga importante para atingir seu propósito comunicativo. Como já observado, a essa estratégia a GDF denomina Ênfase. Em outras palavras, nem representa uma estratégia para enfatizar um Conteúdo Comunicado ou um Subato. É a essa propriedade de nem que os autores se referem ao afirmarem que construções com nem têm um significado "denso, marcado" (Neves, 2000) ou "é marcada" (Rosário, 2009).

De fato, ao comparar as orações em (30)a e b e (31) a e b, por exemplo, é possível verificar que as estruturas com nem são intensificadas em oposição às estruturas com não.

(30) a. $O$ que não pode nem deve é continuar a atual norma antiquada e retrograda, em que o fornecedor vende por preços bem elevados, porque tem no governo um pagador relapso por várias implicações [1CARredatorXX2CE]

b. O que não pode (e) não deve é continuar a atual norma antiquada e retrograda, em que o fornecedor vende por preços bem elevados, porque tem no governo um pagador relapso por várias implicações.

(31) a. Eu nunca pedi utencilios para a minha Aua, nem caza ou alugueres para se pagar. [1CARleitorXIX1CE]

b. Eu nunca pedi utencilios para a minha Aua, não (pedi) caza ou alugueres para se pagar.

A categoria pragmática de Ênfase expressa por nem é claramente observada em estruturas como (34), em que fica evidente que o uso de nem representa a intenção do Falante de intensificar e não apenas de negar o conteúdo comunicado "esse pedante estudou lógica", o que poderia ser feito por meio do operador não, como mostra a paráfrase em (34a):

(34) este pedante nem Logica estudou [CARleitorXIX1PE-4]

a. este pedante não estudou Logica. 
Essas constatações indicam que nem representa uma categoria pragmática de intensificação e, ao mesmo tempo, uma categoria semântica, indicativa de polaridade negativa, tal como não. Em termos de GDF, essas duas categorias, formuladas respectivamente nos níveis Interpessoal e Representacional, são codificadas, no Nível Morfossintático, cumulativamente pela partícula nem. O que diferencia nem de não é justamente sua propriedade de operador de Ênfase. Dessa forma, pode-se afirmar que, no Nível Morfossintático, nem é uma partícula que mapeia o operador enfático de polaridade negativa e não uma conjunção aditiva, como é comumente considerada.

\section{Considerações finais}

Como observado na literatura, nem é considerado uma conjunção que está presente em estruturas coordenadas e correlatas, atribuindo um significado "denso", "marcado" às estruturas das quais faz parte.

Este artigo propôs-se a discutir o estatuto desse item, apontando discordâncias em relação ao tratamento verificado na tradição linguística. Como se pôde observar, as orações com nem não são correlatas, visto que não há relação de interdependência entre elas nem criação de expectativa de acréscimo de um segundo elemento, como exigido pela correlação. Por outro lado, também não se pode afirmar que seja uma conjunção que relaciona aditivamente dois ou mais membros, visto que a ligação entre eles é efetuada por justaposição ou por meio da conjunção aditiva $e$.

Acreditamos ter deixado claro que nem, na verdade, expressa, no Nível Morfossintático, duas categorias gramaticais: uma do Nível Interpessoal, a Ênfase, e uma do Nível Representacional, a polaridade negativa. Em outras palavras, seguindo o modelo descendente da GDF, o operador de Ênfase e o operador de polaridade negativa, formulados respectivamente no Nível Interpessoal e no Representacional, são codificados no Nível Morfossintático pela partícula nem.

O que diferencia as partículas morfossintáticas não e nem é o fato de a primeira indicar apenas a categoria semântica de polaridade negativa, e a segunda, acumular dois significados, um interpessoal (Ênfase) e outro semântico (polaridade negativa).

Dessa forma, pode-se afirmar com certeza que nem não constitui uma função, geralmente mapeada, no Nível Morfossintático, por uma conjunção, como 
tradicionalmente é definido na literatura. Em outros termos, não se trata de uma conjunção aditiva, mas de uma partícula que representa cumulativamente o operador de ênfase e o operador de polaridade negativa.

\title{
El estatuto de nem (ni) en la gramática del português
}

\begin{abstract}
Resumen
Desde un punto de vista tradicional 'nem' ('ni') ha sido considerada una conjunción copulativa, pues se comprende que establece entre elementos una relación de cópula. Desde un punto de vista etimológico, proviene del latín 'nec', uno de los pocos enlaces que restaron en las variedades vernáculas del latín, aparte de 'et', 'aut', 'magis', 'ca', 'post' (cf. NASCENTES, 1955). Según Neves (2000), 'nem' ('ni') desempeña el mismo papel de 'e' ('y/e'), es decir, se trata de una conjunción que marca una relación de cópula entre segmentos negativos coordinados, con significado básico de 'e também não' ('y tampoco/y también no'). Como se observa, la autora considera 'nem' ('ni') un elemento complejo que señala añadidura por medio de 'e' ('y/e') y ‘também' ('también'), y negación, por medio de 'não' ('no’). Este trabajo presenta como objetivo discutir el estatuto de ese elemento a la luz de la teoría de la Gramática Discursivo-Funcional (HENGEVELD; MACKENZIE, 2008), bajo la hipótesis de que 'nem' ('ni'), de la misma manera que 'não' ('no'), representa, morfosintácticamente, el operador de polaridad negativa, añadida, sin embargo, de énfasis. Para ello, se utiliza el corpus del Proyecto PHPB, constituido de documentos escritos en Brasil del siglo XVII al XX. Los datos analizados muestran que 'nem' ('ni') puede darse en la relación de yuxtaposición entre actos discursivos o entre términos de distintas categorías semánticas y representa, además de la negación, una estrategia de intensificación, utilizada por el hablante para lograr éxito en su propósito comunicativo.
\end{abstract}

Palabras clave: Ni. Coordinación copulativa. Polaridad. Énfasis.

\section{Referências}

BECHARA, E. Moderna gramática portuguesa. Rio de janeiro: Lucerna, 2004. CUNHA, C.; CINTRA, L. Nova gramática do português contemporâneo. Rio de Janeiro: Nova Fronteira, 2001. 
HENGEVELD, K.; MACKENZIE, J. L. Functional Discourse Grammar: A typologically-based theory of language structure. Oxford: Oxford University Press, 2008.

MÓDOLO, M. Correlação: Estruturalismo versus Funcionalismo. (Pré) publications: forskning og undervisning. Danmark: Romansk Institut, Aarhus Universitet, 1999.

NEVES, M. H. M. Gramática de usos do português. São Paulo: Editora UNESP, 2000.

OITICICA, José. Teoria da correlação. Rio de Janeiro: Organizações Simões, 1952.

RODRIGUES, V. V. Correlação. In: VIEIRA, S. R.; BRANDÃO, S. F. (orgs.). Ensino de gramática: descrição e uso. São Paulo: Contexto, 2007.

RODRIGUES, V. V. Correlação. Em foco a correlação. Revista Diadorim. Volume 16, Dezembro 2014.

ROSÁRIO, I. C. Construções aditivas: uma análise funcional. In: Pesquisa em Linguística Funcional: convergências e divergências. Rio de Janeiro: Leo Christiano Editorial, 2009. 1 CD ROM

Submetido: 30/03/2016

Aceite: 08/07/2016 